\title{
以太阳活动区模糊分类为基础的 耀斑预报的评价
}

\author{
刘绪昭董士伦
}

(中国科学院北京天文台)

笔者之一(刘绪昭 ${ }^{(1)}$ ) 在活动区模糊分类基础上进行了太阳耀猛预报工作的尝试. 在本文 中, 我们分析文献 [1] 的结果. 首先, 我们用相关分析讨论所选取的因子, 然后引进在心理学 和气象学中所用的 ROC 方法评定文献 [1] 中预报的优劣.

\section{一、相关分 析}

在文献 [1] 中,模糊分类使用了活动区的 7 个物理量（即活动区模糊矢量的 7 个分量 $X_{i}$, $i-1, \cdots 7$ ) 依次为活动区的苏黎世分类, 黑子群面积, 最大场强, 威尔逊磁分类, 形态 (反常 结构), 活动区 $3 \mathrm{~cm}$ 射电辐射流量及 $3 \mathrm{~cm}$ 与 $10 \mathrm{~cm}$ 流量之比. 我们根据文献 [1] 中活动区的 模糊矢量与耀斑发生率的关系 (见文献 [1] 中表). 按式 (1) (可见于一般教科书)计算活动区 的模糊矢量的分量和该活动区次日产生耀的概率的相关系数 $r$, 以检验我们模糊矢量的选 取,并讨论相应的物理意义.

为检验量 $\boldsymbol{x}$ 与 $\boldsymbol{y}$ 的线性相关程度可按下式计算相关系数

$$
r=\frac{\bar{z}\left(x_{j}-\bar{x}\right)\left(y_{j}-\bar{y}\right)}{\left[\bar{z}\left(x_{i}-\bar{x}\right)^{2} * \bar{z}\left(y_{i}-\bar{y}\right)^{2}\right]^{1 / 2}},
$$

其中 $\bar{x}, \bar{y}$ 表示平均值, $j=1,2, \cdots n$ 表示测量序数.

表 1 即按式 (1) 和文献 [1] 中活动区模糊分类表计算的相关系数. 由表 1 可见, 䧽斑发 生概率主要与 $x_{1}, x_{2}, x_{3}$ 和 $x_{7}$ 相关, 其次是 $x_{6}$. 换言之, 活动区耀珓发生率主要涉及活动区 的黑子群类型、面积、最大场强和 $3 \mathrm{~cm}$ 射电流量与 $10 \mathrm{~cm}$ 射电流量之比, 其次与活动区 $3 \mathrm{~cm}$ 射电流量相关.

$x_{7}$ 与 $x_{1} ， x_{2}, x_{3}$ 相关显著,另外还与 $x_{6}$ 相关. 此量不易取得,在实用时可舍去.

$x_{6}$ 与 $x_{1}, x_{2}, x_{3}$ 相关较弱, 而与 $x_{7}$ 及活动区产生耀斑的概率较为相关. 由此可见活动区 $3 \mathrm{~cm}$ 射电通量对于活动区分类及预报是个有意义的因子.

量 $x_{1}, x_{2}, x_{3}$ 彼此相关显著,在使用时可舍去其中 1 个因子. 例如, 在此保留 $x_{2}$ (黑子群 面积)和 $x_{3}$. (最大场强). 因此, 可以认为, 活动区中耀斑的发生与它的总磁通量密切相关.

相关分析还表明, 磁结构因子 $\left(x_{4}, x_{5}\right)$ 与耀的发生概率相关不强. 在文献 [1] 中的椎 是指 1 级和 1 级以上的耀琉, 而实际上, 大部分都是 1 级耀玟. 其它研究 ${ }^{[2,3]}$ 中指出的与磁 结构因子相关的耀斑都是大耀斑, 特别是质子耀斑. 这表明小耀琣与大耀玨所要求的物理背

本文1986 年12月5日收到。 
表 1 活动区模糊矢量的分量与酒珽发生硫率间的相关系数

\begin{tabular}{|c|c|c|c|c|c|c|c|c|}
\hline$r$ & $x_{i}$ & $x_{2}$ & $x_{3}$ & $x_{4}$ & $x_{3}$ & $x_{0}$ & $x_{1}$ & $y^{*}$ \\
\hline$x_{1}$ & 1 : & 0.93 & 0.83 & 0.33 & -0.003 & .0 .41 & .0 .90 & 0.92 \\
\hline$x_{2}$ & & 1 & 0.89 & 0.26 & 0.05 & 0.54 & 0.92 & 0.90 \\
\hline$x_{3}$ & & & 1 & 0.40 & 0.14 & 0.35 & 0.72 & 0.81 \\
\hline$x_{4}$ & & & & 1 & -0.04 & 0.21 & 0.32 & 0.46 \\
\hline$x$, & & & & & 1 & -0.17 & 0.04 & 0.05 \\
\hline$x_{0}$ & & & & & & 1 & 0.67 & 0.64 \\
\hline$x_{2}$ & & & & & & & 1 & 0.93 \\
\hline$y$ & & & & & & & & 1 \\
\hline
\end{tabular}

- y系活动区次日产生相展的概率。

贯,乃至于产生机理是相异的.

\section{二、ROC 分析}

如同确定气象预报质量一样，太阳活动预报质量也是难于表明的. 如所周知, 太阳活动预 报不能简单地以报准率, 漏报率,或其它单一指数表示. 预报质量的判断也依赖于服务对象的 要求。

一种源出于心理学的判断方法,现已在判断理论、电子学、心物学和气象学 ${ }^{[4,53}$ 中都得到了 广泛的应用. 该方法可简称为 ROC/SDT 方法或 ROC 分析 (Relative Operating Characteristic, ROC; Signal Detection Theory, SDT). 美国空间环境服务中心也已将 ROC 分析用 于判断太阳活动预报员的预报水平 ${ }^{[6]}$.

ROC 是一种曲线图, 显示出随判定标准变化而引起命中率(报准活动区产生耀斑次数与 与实际耀斑数之比)，误警率(误报活动次数与无活动数之比)的交替. ROC 图易于显示出预 报水平.

在文献 [1] 表中列出的预报结果是按每日日面各活动区的物理量预报次日日面是否出现 耀斑. 在判定这样的预报质量时会出现相当的含混，例如预报活动区 A 次日出现耀斑概率很 大，而实际上耀玟出现在预报概率极小的活动区 B. 这对于文献 [1] 的预报是一次成功的预

荠 2 活动区耀琣预报命中率和误警率统计的结果

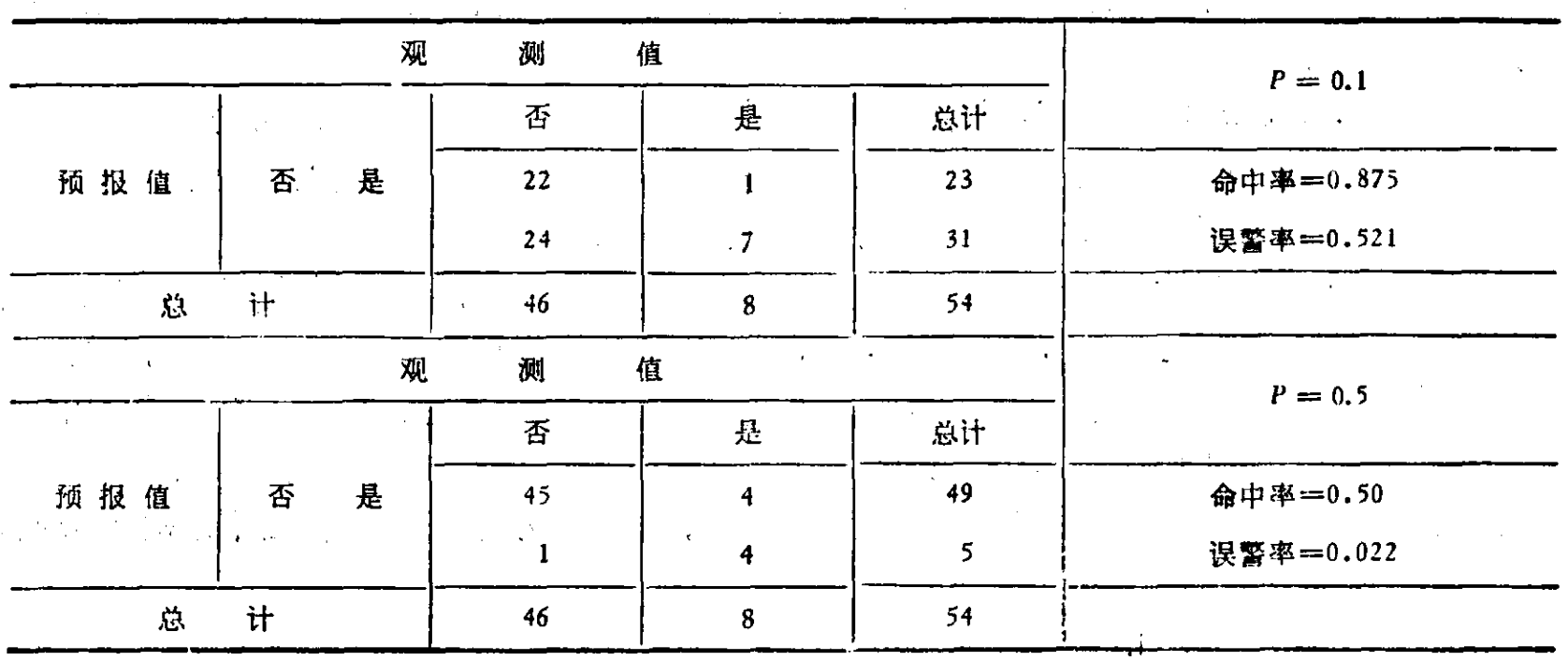


报, 实际上是有问题的. 在本文中我们按逐个活动区计数. 在进行 ROC 分析时,报整标准取 为耀斑产生概率为 $P=0.1,0.3,0.4,0.5,0.7$. 表 2 为按文献 [1] 资料, 取 $P$ 为 0.1 和 0.5 的 统计结果(其余从略).

按对 $P=0.1,0.3,0.4,0.5,0.7$ 统计的结果绘出 ROC 图 (图 1). 图 1 的结果表明文献 [1] 的预报交杲是较好的,特别是要求较低误警率时，可得到较高的命中率. 图中“*”所对应 的点是文献 [1] 中按整个日面预报的结果 (见表 3). 当然这个结果是相当好的. 但如上所指 出. 其中包括一些含混, 另一方面也与统计日数少有关.

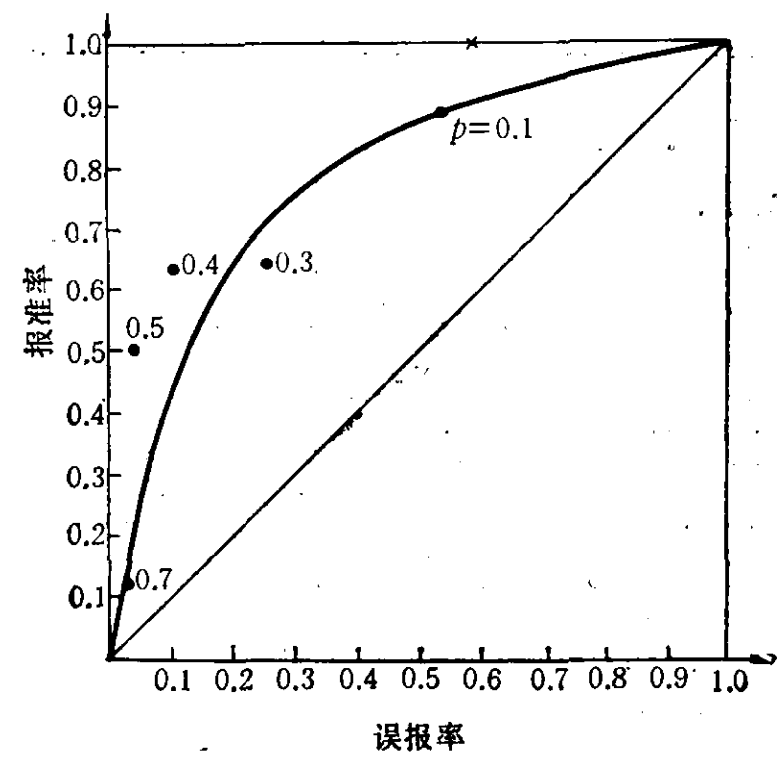

图 1 太阳耀斑预报的 ROC 图

表 3 日面耀斑预报命中事和误紫率的统计

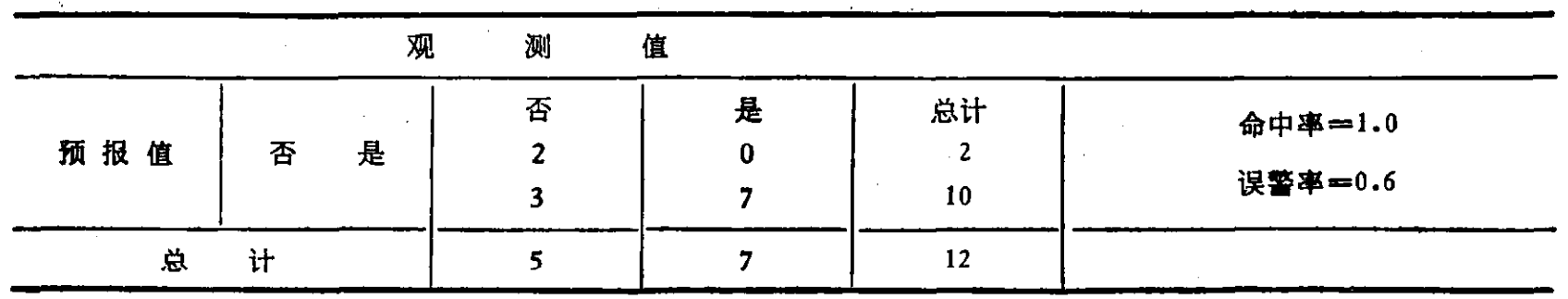

\section{* 文 草}

[1]刘绪昭、李威，天体物理学报，7(1987),55.

[2]林元璋,太阳耀酷(第15章)，1983.

[3]陈协玢、赵爱娣，太阳物理和射电天文座谈会报告透编，1973.

[4] Murphy, A. H., Aust. Met. Mag., 30(1982), 291.

[5] Swets, J.A. and Ronald, M.P., Evolution of Diagnostic Systems: Methods from Signal Detection Theory, Academic Press, N. Y., 1982.

[6] Heckman, G., 在华报告, 1986 . 